\title{
Rancang Bangun Sistem Informasi Geografis untuk Pemetaan Lokasi Tempat Ibadah di Kota Mataram Menggunakan Metode Extreme Programming
}

\author{
(Design of Geographic Information System for Mapping the Location of Worship in \\ Mataram City Using Extreme Programming Method)
}

Ricky Satria*, Royana Afwani, Sri Endang Anjarwani

Dept Informatics Engineering, Mataram University

Jl. Majapahit 62, Mataram, Lombok NTB, INDONESIA

Email: rickyinformatika16@gmail.com, [royana, endang]@unram.ac.id

\section{"Penulis korespondensi}

\begin{abstract}
In Mataram city, finding places of worship is quite difficult for foreigners because they do not know the position/road around them. And currently, the data management of places of worship is still carried out using Ms. Excel by the Departemen Agama NTB which makes data collection ineffective and inefficient in searching and updating existing data. In this final project research, the researcher designed and built a Geographic Information System for Mapping the Location of Places of Worship in Mataram City to provide information and layout of places of worship in Mataram City, and can make it easier for the Ministry of Religion to collect data from the system that makes data management of existing places of worship more effective and efficient. This final project research uses the Extreme Programming (XP) system development method because one of the characteristics of XP itself involves the client during the system development process to minimize errors in the system and according to client needs.
\end{abstract}

Key words: Sistem Informasi Geografis, Kota Mataram, Tempat Ibadah, Metode Extreme Programming

\section{PENDAhUluan}

Tempat ibadah merupakan suatu tempat bertemunya para umat beragama untuk beribadah menurut ajaran agama atau kepercayaan mereka masing-masing [1]. Tempat peribadatan setiap harinya atau waktu tertentu selalu banyak dikunjungi oleh umatnya[2]. Sarana peribadatan seperti rumah ibadah merupakan bangunan yang memiliki ciri-ciri tertentu yang khusus dipergunakan untuk beribadat bagi para pemeluk agama masingmasing[3].

Berdasarkan kuesioner yang telah dilakukan terhadap 61 responden, $55,7 \%$ data responden menyatakan bahwa fungsi rumah ibadah yaitu digunakan bagi seseorang yang hendak ingin meningkatkan hubungan spritual dengan Tuhan-Nya dan 34,4\% data responden menyatakan rumah ibadah digunakan bagi orang muslim yakni untuk mendapatkan lebih banyak pahala daripada sholat di rumah. $62,3 \%$ data responden menyatakan cukup sulit dalam melakukan pencarian tempat ibadah di Kota Mataram, yang disebabkan karena $68,8 \%$ data responden menunjukkan bahwa mereka tidak mengetahui posisi/jalan di sekitar mereka berada. Adapun berbagai macam solusi yang dilakukan masyarakat saat ini dalam mengatasi masalah tersebut yaitu $34,4 \%$ data responden memilih bertanya kepada penduduk sekitar, $32.8 \%$ memilih untuk menelusuri jalanan dan 29.5\% memilih untuk menggunakan google maps. $75,4 \%$ data respoden berpendapat bahwa mengetahui informasi lokasi tempat ibadah sangatlah penting untuk memenuhi kewajiban peribadatan. Untuk mengetahui penting atau tidaknya dibangun Sistem Informasi Geografis (SIG) untuk Pemetaan Lokasi Tempat ibadah di Kota Mataram, didapatkan hasil data responden $54.1 \%$ berpendapat sangat penting $44.3 \%$ berpendapat penting, dan $1.6 \%$ berpendapat kurang penting. Dilihat dari hasil kuesioner tersebut dapat dikatakan bahwa masyarakat setuju untuk dibangunnya sistem informasi pemetaan lokasi tempat ibadah di Kota Mataram tersebut. Dan 75,4\% data responden memilih untuk dibuatkan sistem berbasis android, karena lebih efektif dan efisien dalam penggunaannya.

Berdasarkan hasil wawancara yang telah dilakukan terhadap salah satu staff sub. bagian Inmas Kementerian Agama provinsi NTB yaitu bapak H. Toni, menyebutkan bahwa dalam pengelolaan data informasi mengenai tempat ibadah yang ada saat ini masih menggunakan cara konvensional yaitu menggunakan Ms. Excel, sehingga pendataan sering kali tidak efektif serta membutuhkan waktu yang cukup lama ketika melakukan pencarian terhadap data-data yang ada. Berdasarkan observasi yang penulis lakukan juga tidak adanya media informasi dan pemetaan tempat ibadah di Kota Mataram, sistem informasi geografis untuk lokasi tempat ibadah di Kota Mataram juga masih belum ada. 
Dalam penelitian ini, SIG sangat cocok untuk mengatasi masalah yang telah dipaparkan sebelumnya, guna untuk memberikan informasi dan tata letak mengenai tempat ibadah yang ada di Kota Mataram karena saat dilakukan pencarian tempat ibadah berarti letak geografisnya yang lebih utama dibutuhkan.

Digunakan metode Extreme Programming pada penelitian ini karena terdapat model Personal Extreme Programming atau PXP yang proses pengembangannya dapat dilakukan oleh programmer tunggal, dimana dalam kasus penelitian ini dikerjakan oleh penulis sendiri. Dalam XP menekankan konsep lebih berinteraksi dengan client dalam proses pengambangan sistem dan berfokus pada sistem yang dikembangkan, sehingga meminimalisir terjadinya kesalahan pada sistem dan sesuai dengan kebutuhan client, dalam kasus penelitian ini pihak Kementerian Agama prov. NTB sebagai client.

Berdasarkan hal tersebut, maka penulis akan merancang dan membangun suatu sistem informasi geografis yang berjudul "Rancang Bangun Sistem Informasi Geografis Untuk Pemetaan Lokasi Tempat Ibadah Di Kota Mataram Menggunakan Metode Extreme Programming". Diharapkan setelah terciptanya sistem ini nantinya dapat membantu pihak Kemenag prov. NTB dalam mengelola data informasi tempat ibadah yang ada serta membantu masyarakat umum dalam mengetahui informasi dan lokasi mengenai tempat ibadah yang ada di Kota Mataram dengan mudah.

\section{TINJAUAN PUSTAKA}

Adapun sistem informasi mengenai tempat ibadah yang telah dibuat oleh peneliti terdahulu diantaranya adalah sebagai berikut:

Penelitian yang berjudul "Implementasi Geographic Information System (GIS) Penentuan Tampat Ibadah Masjid Di Kecamatan Kempas Kabupaten Indragiri Hilir Provinsi Riau" yang bertujuan untuk dapat membantu masyarakat terutama yang berasal dari luar kota Kecamatan Kempas maupun dari daerah-daerah lain untuk menemukan suatu tempat ibadah di daerah Kecamatan Kempas. Aplikasi WebGis ini dibuat dengan menggunakan GIS, Dreamuwever CS 5, MySql, dan Web Browser sebagai media untuk menyajikan informasinya. Dimana informasi yang disajikan hanya informasi mengenai lokasi atau letak tempat ibadah masjid saja yang ada di Kecamatan Kempas. Untuk metode pengembangan sistem yang digunakan yaitu SDLC (System Development Life Cycle). SDLC merupakan metodologi klasik yang digunakan oleh analis sistem dan programmer dalam mengembangkan, memilihara, dan menggunakaan sistem informasi [8].

Pada penelitian yang berjudul "Sistem Informasi Geografis Persebaran Tempat Ibadah Dan Kapasitasnya Berdasarkan Jumlah Penduduk Di Kota Banjarmasin" merupakan suatu pembangunan sistem informasi geografis tempat ibadah berbasis web dengan menggunakan datadata yang didapatkan dari Kementrian Agama Kota Banjarmasin, serta peta administrasi Kota Banjarmasin.
Aplikasi WebGis ini dibangun menggunakan Quantum GIS dan Google Maps. Dengan adanya aplikasi ini akan dapat dijadikan pertimbangan untuk pengambilan keputusan dalam menentukan layak atau tidak untuk mendirikan tempat ibadah baru di Kota Banjarmasin [9].

Dalam penelitian yang berjudul "Sistem Informasi Masjid Di Surakarta" dibangun untuk menampilkan informasi mengenai masjid yang ada di Surakarta. Dimana tujuannya tidak hanya untuk memberikan kemudahan kepada masyarakat untuk mencari informasi seputar masjid di Surakarta, tetapi juga digunakan pihak IT di Kementrian Agama Kantor Kota Surakarta untuk memantau segala sesuatu yang ada di dalam website serta dapat menyebarluaskan informasi menjadi lebih efektif dan efisien. Aplikasi berbasis website ini dibangun menggunakan bahasa pemrograman PHP dan MySQL untuk penyimpanan database-nya, serta untuk user interface-nya dibangun menggunakan bahasa pemrograman HTML dan CSS. Website pada penelitian ini dilengkapi fitur searching, maps, dan newsfeed [10].

Pada penelitian yang berjudul "Membangun Aplikasi WebGis Untuk Tempat Ibadah Di Provinsi Lampung" yang membahas tentang pembuatan aplikasi WebGis yang dapat digunakan untuk mencari tempat ibadah yang ada di Lampung secara online. Aplikasi pada penelitian ini dibangun menggunakan bahasa pemrograman HTML dan PHP dengan database MySql. Untuk metode pengembangan sistem yang digunakan yaitu Extreme Programming. Extreme Programming adalah sebuah pendekatan atau model pengembangan perangkat lunak yang mencoba menyederhanakan berbagai tahapan dalam proses pengembangan tersebut sehingga menjadi lebih adaptif dan fleksibel [5].

Dalam penelitian yang berjudul "Perancangan Sistem Informasi Tempat Ibadah Beragam Agama Di Kota Solo" yang membahas tentang pembuatan sistem informasi berbasis website yang berguna untuk menampilkan dan memuat informasi tempat ibadah beragam agama di Kota Solo, yaitu: Masjid, Gereja, Pura, Vihara, dan Kelenteng. Sistem informasi berbasis website ini Dibangun menggunakan bahasa pemrograman PHP dan database MySql. Untuk metode pengembangan sistem yang digunakan yaitu metode waterfall [5].

Penelitian yang berjudul "Sistem Informasi Geografis Pemetaan Masjid Di Samarinda Berbasis Web" merupakan suatu pembangunan sistem informasi geografis pemetaan masjid berbasis web yang bertujuan untuk memberikan informasi kepada masyrakat yang ada di Samarinda tentang tempat ibadah masjid beserta kegiatan yang ada didalamnya dalam visualisasi peta menggunakan Google Maps API dan terdapat fitur rute yang menggambarkan rute arah jalan dari posisi user berada menuju lokasi masjid yang diinginkan. Aplikasi pada penelitian ini dibuat menggunakan bahasa pemrograman PHP dan untuk database-nya menggunakan MySQL. Untuk metode pengembangan sistem yang digunakan yaitu waterfall. Waterfall memiliki beberapa tahapan dalam pengembangan sistem yang dilakukan, yakni: tahap 
perencanaan, tahap analsis, tahap perancangan, tahap penerapan, tahap pengujian dan tahap pemeliharaan[11].

Berdasarkan tinjauan pustaka yang telah dipaparkan, penulis akan merancang dan membangun Sistem Informasi Geografis Untuk Pemetaan Lokasi Tempat Ibadah di Kota Mataram menggunakan metode Extreme Programming. Studi kasus ini diambil karena belum ada penelitian tentang SIG pemetaan lokasi tempat ibadah di Kota Mataram. Tujuan dari penelitian ini yaitu untuk mempermudah masyarakat umum dalam mencari mencari tau informasi dan lokasi tempat ibadah yang diinginkan serta memudahkan pihak Kemenag prov. NTB dalam mengelola data tempat ibadah yang ada.

\section{Metode PENELITIAN}

\section{A. Alat dan Bahan}

\section{A.1. Alat}

1. Laptop ACER Aspire 4739 dengan processor Core i3 2.4GbHz hardisk $500 \mathrm{~Gb}$ menggunakan OS (operating system) Windows 10 Pro.

2. CodeIgniter, merupakan framework bahasa pemrograman PHP yang digunakan untuk membangun sistem berbasis $w e b$.

3. XAMPP, sebagai peneydia localhost web server.

4. MySQL, sebagai server database.

5. Visual Studio Code, sebagai text editor pada saat melakukan proses coding.

6. Microsoft Word 2016, digunakan untuk menyusun laporan.

7. Microsoft Visio 2016, digunakan untuk membuat rancangan diagram.

8. Mendeley, digunakan untuk membuat sitasi dan daftar pustaka.

9. Postman, digunakan sebagai tester terhadap penyedia layanan API.

10. Android Studio, digunakan untuk membangun sistem berbasis android.

\section{A.2. Bahan}

1. Data setiap tempat ibadah yang ada di Kota Mataram beserta deskripsinya.yang didapat dari kemenag NTB.

2. Data latitude dan longitude tempat ibadah di Kota Mataram.

\section{B. Diagram Alir Penelitian}

Pada penelitian ini menggunakan metodologi pengembangan sistem Extreme Programming yang terdiri dari 4 tahapan yaitu : planning, design, coding, dan testing. Tahap-tahap pengembangan sistem tersebut diilustrasikan pada diagram alir penelitian pada Gambar 1.

\section{B.1. Studi Literartur}

Tahap pertama dalam penelitian ini adalah studi literatur. Studi literatur dilakukan dengan mengumpulkan data dan memahami teori-teori dari berbagai buku, skripsi, jurnal dan penelitian-penelitian sebelumnya yang berkaitan dengan pembuatan dan perancangan aplikasi pemetaan tempat ibadah pada penelitian ini.

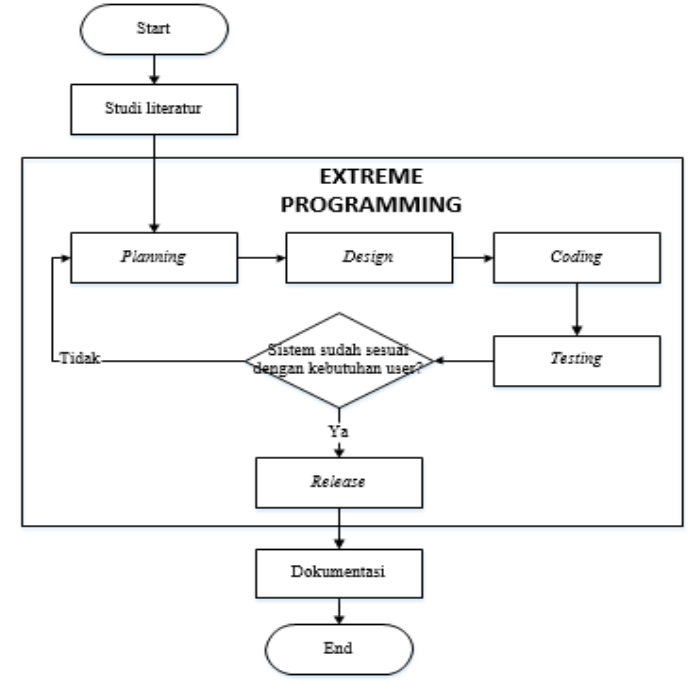

Gambar 1. Diagram Alir Penelitian

\section{B.2. Planning}

Pada tahap ini merupakan analisa terhadap kebutuhan dalam pengembangan sistem yang akan dibuat dan perencanaan untuk mendapatkan gambaran fitur dan fungsi dari perangkat lunak yang akan dibangun (user stories). User story card yang baik menerapkan model INVEST yaitu Independent, Negotiable, Valuable, Estimable, dan Small. Independent berarti tidak adanya ketergantungan antar user story, Negotiable berarti seluruh detil diperoleh melalui kolaborasi, Valuable berarti memiliki nilai bagi pengguna, Estimable berarti dapat diperkirakan baik dalam segi waktu dan biaya, Testable berarti dapat ditentukan acceptance criteria-nya. Sebuah user story dapat dikatakan "selesai" jika acceptance criteria user story tersebut telah dipenuhi[30].

Rangkuman dari user story yang akan dibuat pada sistem yang diperoleh dari klien dapat dilihat pada Tabel I.

TABEL I. RANGKUMAN USER STORIES

\begin{tabular}{|c|c|l|c|}
\hline No & $\begin{array}{c}\text { Kode } \\
\text { US }\end{array}$ & \multicolumn{1}{|c|}{ Deskripsi } & $\begin{array}{c}\text { Estimasi } \\
\text { (hari) }\end{array}$ \\
\hline 1 & US-01 & $\begin{array}{l}\text { Terdapat 2 jenis sub. Bagian yaitu } \\
\text { Bimas Islam yang berperan sebagai } \\
\text { admin dan Inmas yang berperan } \\
\text { sebagai super admin yang dapat masuk } \\
\text { ke dalam sistem. Dan admin dapat } \\
\text { logout dari system }\end{array}$ & 4 \\
\hline 2 & US-02 & $\begin{array}{l}\text { Sebagai Super Admin, saya dapat } \\
\text { melihat daftar admin berupa list admin } \\
\text { serta deskripsinya. }\end{array}$ & 2 \\
\hline 3 & US-03 & $\begin{array}{l}\text { Sebagai Super Admin, saya dapat } \\
\text { menambah data admin baru beserta } \\
\text { deskripsinya. }\end{array}$ & 2 \\
\hline 4 & US-04 & $\begin{array}{l}\text { Sebagai Super Admin, saya dapat } \\
\text { mengubah data admin. }\end{array}$ & 2 \\
\hline 5 & US-05 & $\begin{array}{l}\text { Sebagai Super Admin, saya dapat } \\
\text { menghapus data admin. }\end{array}$ & 2 \\
\hline 6 & US-06 & $\begin{array}{l}\text { Sebagai Super Admin, Admin, dan } \\
\text { masyarakat saya dapat melihat daftar } \\
\text { tempat meliputi nama tempat ibadah } \\
\text { dan deskripsinya }\end{array}$ & 6 \\
\hline
\end{tabular}




\begin{tabular}{|c|l|l|c|}
\hline No & $\begin{array}{l}\text { Kode } \\
\text { US }\end{array}$ & Deskripsi & $\begin{array}{c}\text { Estimasi } \\
\text { (hari) }\end{array}$ \\
\hline 7 & US-07 & $\begin{array}{l}\text { Sebagai Super Admin, dan Admin, } \\
\text { saya dapat menambah data tempat } \\
\text { ibadah baru beserta deskripsinya. }\end{array}$ & 2 \\
\hline 8 & US-08 & $\begin{array}{l}\text { Sebagai Super Admin, dan Admin, } \\
\text { saya dapat mengubah data tempat } \\
\text { ibadah. }\end{array}$ & 2 \\
\hline 9 & US-09 & $\begin{array}{l}\text { Sebagai Super Admin, dan Admin, } \\
\text { saya dapat menghapus data tempat } \\
\text { ibadah. }\end{array}$ & 2 \\
\hline 10 & US-10 & $\begin{array}{l}\text { Masyarakat sebagai pengguna, saya } \\
\text { dapat mengakses lokasi terkini }\end{array}$ & 3 \\
\hline 11 & US-11 & $\begin{array}{l}\text { Masyarakat sebagai pengguna, saya } \\
\text { dapat mengakses rute / jalur menuju } \\
\text { tempat ibadah }\end{array}$ & 3 \\
\hline
\end{tabular}

\section{B.3. Design}

Pada penelitian ini, sistem dirancang dengan menggunakan UML yaitu Class Responsibilities Collaboration Card (CRC-Card) untuk mengetahui interaksi atau hubungan antar objek yang ada pada sistem. Digunakannya CRC-Card pada metode XP adalah karena mengacu pada nilai kesederhanaan yang ada pada metode XP itu sendiri[26]. Penjelasan CRC-Card pada penelitian ini dapat dilihat pada Tabel II.

\section{TABEL II. PENJELASAN CRC-CARD}

\begin{tabular}{|c|c|c|c|}
\hline Nama & Class & Responsibilities & Collaborator \\
\hline \multirow[t]{4}{*}{$\begin{array}{l}\text { Tempat } \\
\text { ibadah } \\
\text { basis web }\end{array}$} & $\begin{array}{l}\text { C Tempat } \\
\text { Ibadah }\end{array}$ & $\begin{array}{l}\text { Mengatur jalannya data } \\
\text { tempat ibadah yang akan } \\
\text { dikelola maupun yang } \\
\text { akan ditampilkan pada } \\
\text { sistem. }\end{array}$ & $\begin{array}{l}\text { M tempat } \\
\text { ibadah, } \\
\text { V daftar } \\
\text { tempat ibadah }\end{array}$ \\
\hline & $\begin{array}{l}\text { M tempat } \\
\text { ibadah }\end{array}$ & $\begin{array}{l}\text { Digunakan untuk } \\
\text { mengambil dan } \\
\text { mengelola data tempat } \\
\text { ibadah seperti } \\
\text { menambah, mengubah } \\
\text { serta menghapus data } \\
\text { tempat ibadah dalam } \\
\text { database. }\end{array}$ & $\begin{array}{l}\text { C tempat } \\
\text { ibadah }\end{array}$ \\
\hline & $\begin{array}{l}\mathrm{V} \text { daftar } \\
\text { tempat } \\
\text { ibadah }\end{array}$ & $\begin{array}{l}\text { Menampilkan data } \\
\text { tempat ibadah yang } \\
\text { tersusun dalam bentuk } \\
\text { tabel. }\end{array}$ & $\begin{array}{l}\text { C tempat } \\
\text { ibadah, M } \\
\text { Tempat } \\
\text { ibadah }\end{array}$ \\
\hline & $\begin{array}{ll}\text { M } & \text { kab } \\
\text { kec } & \end{array}$ & $\begin{array}{l}\text { Untuk mengambil data } \\
\text { kabupaten dan } \\
\text { kecamatan }\end{array}$ & $\begin{array}{l}\text { C tempat } \\
\text { ibadha }\end{array}$ \\
\hline \multirow[t]{3}{*}{ Admin } & $\mathrm{C}$ admin & $\begin{array}{l}\text { Mengatur jalannya data } \\
\text { admin yang akan } \\
\text { dikelola maupun yang } \\
\text { akan ditampilkan pada } \\
\text { sistem. }\end{array}$ & $\begin{array}{l}\text { M admin, } \mathrm{V} \\
\text { daftar admin }\end{array}$ \\
\hline & $\mathrm{M}$ admin & $\begin{array}{l}\text { Digunakan untuk } \\
\text { mengambil dan } \\
\text { mengelola data admin } \\
\text { seperti menambah, } \\
\text { mengubah serta } \\
\text { menghapus data admin } \\
\text { dalam database. }\end{array}$ & $\mathrm{C}$ admin \\
\hline & $\begin{array}{l}\mathrm{V} \text { daftar } \\
\text { admin }\end{array}$ & $\begin{array}{l}\text { Menampilkan data } \\
\text { admin yang tersusun } \\
\text { dalam bentuk tabel }\end{array}$ & $\begin{array}{l}\mathrm{C} \text { admin, } \mathrm{M} \\
\text { admin }\end{array}$ \\
\hline
\end{tabular}

\begin{tabular}{|c|c|c|c|}
\hline Nama & Class & Responsibilities & Collaborator \\
\hline \multirow[t]{3}{*}{ Login } & $\mathrm{C}$ login & $\begin{array}{l}\text { Mengatur jalannya } \\
\text { validasi pengguna yang } \\
\text { akan mengakses system } \\
\text { dan untuk mengakhiri } \\
\text { system (logout) }\end{array}$ & $\begin{array}{l}\text { M admin, } \\
\text { V login }\end{array}$ \\
\hline & $\mathrm{M}$ admin & $\begin{array}{l}\text { Digunakan untuk } \\
\text { validasi kesesuaian } \\
\text { username dan password } \\
\text { pengguna yang ada pada } \\
\text { database. } \\
\end{array}$ & C login, \\
\hline & $\mathrm{V}$ login & $\begin{array}{l}\text { Menampilkan form } \\
\text { untuk login }\end{array}$ & C login \\
\hline \multirow[t]{4}{*}{ dashboard } & $\begin{array}{l}\mathrm{C} \\
\text { dashboar } \\
\text { d }\end{array}$ & $\begin{array}{l}\text { Untuk mengatur jalannya } \\
\text { data yang akan } \\
\text { ditampilkan pada } \\
\text { halaman dashboard }\end{array}$ & $\begin{array}{l}\text { M tempat } \\
\text { ibadah, V } \\
\text { dashboard }\end{array}$ \\
\hline & $\begin{array}{l}\text { V } \\
\text { dashboar } \\
\text { d }\end{array}$ & $\begin{array}{l}\text { Menampilkan daftar } \\
\text { tempat ibadah dan peta } \\
\text { lokasi serta rute tempat } \\
\text { ibadah. }\end{array}$ & C dashboard \\
\hline & $\begin{array}{l}\text { M tempat } \\
\text { ibadah }\end{array}$ & $\begin{array}{l}\text { Digunakan untuk } \\
\text { mengambil data tempat } \\
\text { dalam database. }\end{array}$ & C dashboard \\
\hline & $\begin{array}{ll}\text { M } & \text { kab } \\
\text { kec } & \end{array}$ & $\begin{array}{l}\text { Untuk mengambil data } \\
\text { kabupaten dan } \\
\text { kecamatan }\end{array}$ & $\begin{array}{l}\text { C tempat } \\
\text { ibadha }\end{array}$ \\
\hline \multirow[t]{3}{*}{ Profile } & C profile & $\begin{array}{l}\text { Untuk menampilkan dan } \\
\text { mengatur jalannya data } \\
\text { profile admin yang telah } \\
\text { login }\end{array}$ & $\begin{array}{l}\mathrm{M} \text { admin, } \\
\mathrm{V} \text { profile }\end{array}$ \\
\hline & V profile & $\begin{array}{l}\text { Untuk menampilkan data } \\
\text { admin yang telah login }\end{array}$ & C profile \\
\hline & M profile & $\begin{array}{l}\text { Untuk mengambil data } \\
\text { admin yang telah login }\end{array}$ & $\mathrm{C}$ profile \\
\hline \multirow[t]{4}{*}{$\begin{array}{l}\text { Tempat } \\
\text { ibadah } \\
\text { basis } \\
\text { android }\end{array}$} & $\begin{array}{l}\text { C Tempat } \\
\text { Ibadah }\end{array}$ & $\begin{array}{l}\text { Berguna sebagai } \\
\text { interface yang ada pada } \\
\text { API agar dapat } \\
\text { terhubung dengan } \\
\text { database }\end{array}$ & $\begin{array}{l}\text { M tempat } \\
\text { ibadah }\end{array}$ \\
\hline & $\begin{array}{l}\text { M tempat } \\
\text { ibadah }\end{array}$ & $\begin{array}{l}\text { Digunakan untuk } \\
\text { mengambil data tempat } \\
\text { ibadah dari database }\end{array}$ & $\begin{array}{l}\text { C tempat } \\
\text { ibadah }\end{array}$ \\
\hline & $\begin{array}{l}\text { List } \\
\text { Fragment }\end{array}$ & $\begin{array}{l}\text { Menampilkan daftar } \\
\text { tempat ibadah dalam } \\
\text { bentuk listview }\end{array}$ & $\begin{array}{l}\text { XML, } \\
\text { adapter, C } \\
\text { tempat ibadah }\end{array}$ \\
\hline & $\begin{array}{l}\text { Map } \\
\text { Fragment }\end{array}$ & $\begin{array}{l}\text { Menampilkan peta lokasi } \\
\text { tempat ibadah dalam }\end{array}$ & $\begin{array}{l}\text { XML, } \\
\text { adapter, C } \\
\text { tempat ibadah }\end{array}$ \\
\hline
\end{tabular}

\section{B.4. Coding}

Setelah mengetahui gambaran fungsi-fungsi kebutuhan dari sistem yang akan dibuat, tahapan selanjutnya adalah proses implementasi rancangan sistem yang sudah dilakukan ke dalam bentuk bahasa pemrograman (coding). Pembuatan untuk basis web pada sistem penelitian ini dibangun dengan bahasa pemrograman PHP menggunakan framework Code Igniter sebagai backend dan template bootsrap untuk frontend. Sedangkan untuk basis android dibangun dengan bahasa pemrograman Kotlin.

Pada fase coding dalam XP terdapat pengujian kode program menggunakan teknik Test Driven Development (TDD) dimana melakukan pengembangan perangkat lunak berdasarkan hasil pengujian yang telah dilakukan, hal ini bermaksud untuk dapat mengurangi waktu pengembangan dan dapat minimalisir adanya bug atau error pada 
aplikasi[26]. TTD memiliki alur kerja seperti Gambar 2 sebagai berikut.

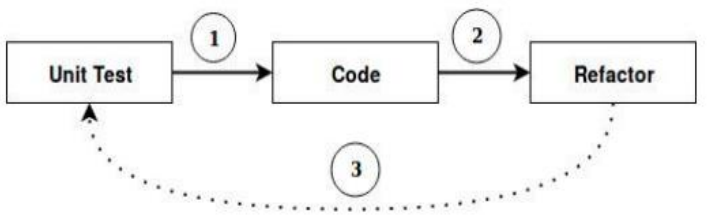

Gambar 2. Alur Kerja TTD

Pengembang menuliskan unit test terlebih dahulu, sesuai spesifikasi dan bisnis proses dari sistem yang diinginkan oleh pengguna (user stories).

Setelah membuat unit test, pengembang menuliskan kode program untuk menyelesaikan unit test sampai pass tidak ada error.

Pengembang melakukan refactoring kode program yaitu mengubah struktur program agar lebih mudah dipahami dan dimodifikasi, tanpa harus mengubah dari behaviour program[33].

\section{B.5. Testing}

Pada tahap ini dilakukan pengujian (testing) untuk mengetahui sistem telah berjalan sesuai dengan rancangan atau tidak. Pengujian yang dilakukan menggunakan alpha testing dengan metode black box dan beta testing dengan penyebaran kuesioner, dimana pengguna akan menilai sejauh mana aplikasi berjalan sesuai dengan tujuan [34]. Digunakan pengujian alpha dan beta karena dirasa cocok atau sesuai dengan tujuan untuk mengetahui sistem yang dikembangkan telah sesuai atau tidak dengan kebutuhan client.

Digunakan 33 responden dalam melakukan kuesioner pada penelitian ini, sebagaimana dikemukakan oleh Cohen, semakin besar sample dari besarnya populasi yang ada adalah semakin baik, akan tetapi ada jumlah batas minimal yang harus diambil oleh peneliti yaitu sebanyak 30 sample [36]. Berikut merupakan tabel skor penilaian dapat dilihat pada Tabel III berikut:

TABEL III. SKOR PENILAIAN

\begin{tabular}{|l|c|}
\hline \multicolumn{1}{|c|}{ Tingkat kepuasan } & Nilai \\
\hline Sangat setuju & 5 \\
\hline Setuju & 4 \\
\hline Cukup & 3 \\
\hline Tidak setuju & 2 \\
\hline Sangat tidak setuju & 1 \\
\hline
\end{tabular}

Untuk melakukan perhitungan kuesioner digunakan Persamaan (1):

$$
\text { Persentase }=\frac{J}{N} * \gamma
$$

Keterangan :

$\mathrm{J}$ : Total nilai jawaban yang diberikan pengguna pada setiap nomor.

$\mathrm{N}$ : Jumlah pengguna
Selanjutnya dilakukan proses perhitungan persentase rata-rata dari setiap poin jawaban, perhitungan yang digunakan adalah menggunakan Persamaan (2).

$$
\begin{aligned}
& \text { Rata }- \text { rata }=\frac{\sum \text { Persentase ke-n }}{6} \\
& \text { IV. HASIL DAN PEMBAHASAN }
\end{aligned}
$$

\section{HASIL DAN PEMBAHASAN}

\section{A. Implementasi metode Extreme Programming}

Dalam proses pengembangan sistem informasi geografis untuk pemetaan lokasi tempat ibadah ini digunakan metode extreme programming seperti yang telah dipaparkan sebelumnya pada diagram alir penelitian pada Gambar 1, guna untuk mengetahui pengembangan sistem mencapai hasil yang diinginkan oleh client.

\section{A.1. Planning}

Pada tahap planning ini sebelumnya pengembang telah melakukan diskusi dengan client untuk mendapatkan user stories yang dimana pada kasus penelitian tugas akhir ini pihak kemenag NTB merupakan client. Tujuan dari user stories ini yaitu untuk mendapatkan gambaran tentang bagaimana system yang dibuat berjalan. Didapatkan total 11 user stories dari client yang telah dipaparkan sebelumnya dapat dilihat pada Tabel I.

Selama proses iterasi berlangsung terdapat beberapa permintaan penambahan user stories dari client seperti yang dirincikan pada Tabel IV berikut:.

TABEL IV. PenAmbahan USER Stories

\begin{tabular}{|c|l|l|c|}
\hline No & Kode US & Deskripsi & $\begin{array}{c}\text { Estimasi } \\
\text { (hari) }\end{array}$ \\
\hline 1 & US-12 & $\begin{array}{l}\text { Sebagai admin, dapat melihat } \\
\text { informasi dan mengubah data diri }\end{array}$ & 4 \\
\hline 2 & US-13 & $\begin{array}{l}\text { Sebagai admin, dapat melihat } \\
\text { halaman beranda dengan total } \\
\text { tempat ibadah }\end{array}$ & 2 \\
\hline 3 & US-14 & $\begin{array}{l}\text { Sebagai admin, dapat } \\
\text { menambahkan data tempat ibadah } \\
\text { dengan cara memasukkan file excel } \\
\text { yang berisi data tempat ibadah, agar } \\
\text { mempermudah penginputan data } \\
\text { dalam jumlah yang banyak }\end{array}$ & 5 \\
\hline 4 & US-15 & $\begin{array}{l}\text { Sebagai admin, dapat mendownload } \\
\text { format excel untuk import data } \\
\text { tempat ibadah, sehingga dapat } \\
\text { menyesuaikan kolom - kolom } \\
\text { masukan data yang diinginkan } \\
\text { sistem }\end{array}$ & 2 \\
\hline 5 & US-16 & $\begin{array}{l}\text { Sebagai admin, dapat melakukan } \\
\text { export excel, sehingga dapat } \\
\text { melakukan pembacaan data tempat } \\
\text { ibadah yang ada dalam bentuk } \\
\text { hardcopy }\end{array}$ & 3 \\
\hline 7 & US-18 & $\begin{array}{l}\text { Sebagai masyarakat, dapat melihat } \\
\text { peta lokasi tempat ibadah pada basis } \\
\text { web, namun terdapat filter } \\
\text { kabupaten yang ada di provinsi } \\
\text { NTB. Sehingga masyarakat juga } \\
\text { mengetahui peta lokasi yang ada di } \\
\text { kabupaten selain di NTB }\end{array}$ & $\begin{array}{l}\text { Sebagai masyarakat, dalam melihat } \\
\text { rute lokasi menuju tempat ibadah } \\
\text { pada basis web }\end{array}$ \\
\hline 6 & US-17 & 2 \\
\hline
\end{tabular}




\section{A.2. Design}

Selanjutnya pada tahap ini akan dibahas mengenai hasil design atau perancangan terdahap user stories yang didapat. Rancangan yang dibuat pengembangan merupakan CRC card seperti yang telah dijabarkan pada tabel 3.3 dan Spike Prototype Solution merupakan skema desain prototype berdasarkan CRC card. Hasil pembuatan design dapat dilihat pada Tabel V.

TABEL V. HASIL DESIGN CRC CARD DAN SPIKE SOLUTION PROTOTYPE

\begin{tabular}{|c|c|c|c|}
\hline Iteration & $\begin{array}{c}\text { Kode } \\
\text { US }\end{array}$ & $\begin{array}{c}\text { Nama } \\
\text { CRC Card }\end{array}$ & $\begin{array}{c}\text { Spike Solution Prototype } \\
\text { Ditujukan gambar }\end{array}$ \\
\hline \multirow[t]{3}{*}{1} & US-01 & Login & $\begin{array}{l}\text { Prototype halaman login } \\
\text { admin }\end{array}$ \\
\hline & US-12 & Profile & $\begin{array}{l}\text { Prototype halaman profile } \\
\text { admin }\end{array}$ \\
\hline & US-02 & Admin & $\begin{array}{l}\text { Prototype halaman melihat } \\
\text { data admin }\end{array}$ \\
\hline \multirow[t]{4}{*}{2} & US-03 & Admin & $\begin{array}{c}\text { Prototype halaman } \\
\text { Menambah data admin }\end{array}$ \\
\hline & US-04 & Admin & $\begin{array}{c}\text { Prototype halaman } \\
\text { Mengubah data admin }\end{array}$ \\
\hline & US-05 & Admin & $\begin{array}{c}\text { Prototype halaman } \\
\text { Menghapus data admin }\end{array}$ \\
\hline & US-07 & $\begin{array}{c}\text { Tempat } \\
\text { ibadah basis } \\
\text { web }\end{array}$ & $\begin{array}{c}\text { Prototype halaman } \\
\text { Menambah data tempat } \\
\text { ibadah }\end{array}$ \\
\hline \multirow[t]{3}{*}{3} & US-14 & $\begin{array}{c}\text { Tempat } \\
\text { ibadah basis } \\
\text { web }\end{array}$ & $\begin{array}{l}\text { Prototype halaman Import } \\
\text { data excel tempat ibadah }\end{array}$ \\
\hline & US-15 & $\begin{array}{c}\text { Tempat } \\
\text { ibadah basis } \\
\text { web }\end{array}$ & $\begin{array}{l}\text { Prototype Unduh template } \\
\text { format excel import data }\end{array}$ \\
\hline & US-16 & $\begin{array}{c}\text { Tempat } \\
\text { ibadah basis } \\
\text { web }\end{array}$ & $\begin{array}{l}\text { Prototype Export data } \\
\text { excel tempat ibadah }\end{array}$ \\
\hline \multirow[t]{3}{*}{4} & US-06 & $\begin{array}{c}\text { Dashboar, } \\
\text { tempat } \\
\text { ibadah basis } \\
\text { web dan } \\
\text { android }\end{array}$ & $\begin{array}{l}\text { Prototype halaman Melihat } \\
\text { daftar tempat ibadah }\end{array}$ \\
\hline & US-13 & $\begin{array}{c}\text { Tempat } \\
\text { ibadah basis } \\
\text { web }\end{array}$ & $\begin{array}{c}\text { Prototype halaman } \\
\text { Beranda halaman admin }\end{array}$ \\
\hline & US-08 & $\begin{array}{c}\text { Tempat } \\
\text { ibadah basis } \\
\text { web }\end{array}$ & $\begin{array}{c}\text { Prototype halaman } \\
\text { Mengubah data tempat } \\
\text { ibadah } \\
\end{array}$ \\
\hline \multirow[t]{3}{*}{5} & US-09 & $\begin{array}{c}\text { Tempat } \\
\text { ibadah basis } \\
\text { web }\end{array}$ & $\begin{array}{l}\text { Prototype Menghapus data } \\
\text { tempat ibadah }\end{array}$ \\
\hline & US-10 & $\begin{array}{c}\text { Tempat } \\
\text { ibadah basis } \\
\text { android }\end{array}$ & $\begin{array}{c}\text { Prototype halaman Melihat } \\
\text { peta lokasi tempat ibadah } \\
\text { basis android }\end{array}$ \\
\hline & US-11 & $\begin{array}{c}\text { Tempat } \\
\text { ibadah basis } \\
\text { android }\end{array}$ & $\begin{array}{l}\text { Prototype halaman Melihat } \\
\text { rute lokasi tempat ibadah } \\
\text { android }\end{array}$ \\
\hline \multirow[t]{2}{*}{6} & US-17 & Dashboard & $\begin{array}{c}\text { Prototype halaman Melihat } \\
\text { peta lokasi tempat ibadah } \\
\text { pada basis web }\end{array}$ \\
\hline & US-18 & Dashboard & $\begin{array}{l}\text { Prototype halaman Melihat } \\
\text { rute menuju lokasi tempat } \\
\text { ibadah pada basis web }\end{array}$ \\
\hline
\end{tabular}

\section{A.3. Coding}

Pada tahap ini dilakukan implementasi (coding) SIG Pemetaan Lokasi Tempat Ibadah. Implementasi yang dilakukan telah dibuat sesuai dengan perancangan yang dijabarkan pada Tabel V. Pada tahap ini juga dilakukkannya pengujian langsung oleh klien mengenai fungsionalitas semua fitur dari sistem yang telah dibangun berdasarkan dengan user stories yang telah dijabarkan oleh klien. Berikut tabel hasil pengujian dapat dilihat pada Tabel VI.

TABEL VI. Hasil Pengujian Black Box

\begin{tabular}{|c|c|c|}
\hline No & Fitur & Hasil uji \\
\hline 1 & Login ke dalam system & Diterima \\
\hline 2 & Mengakhiri system (logout) & Diterima \\
\hline 3 & Melihat dan mengubah profile admin login & Diterima \\
\hline 4 & Melihat daftar data admin & Diterima \\
\hline 5 & Menambah data admin & Diterima \\
\hline 6 & Mengubah data admin & Diterima \\
\hline 7 & Menghapus data admin & Diterima \\
\hline 8 & Menambah data tempat ibadah & Diterima \\
\hline 9 & Mengimport data excel tempat ibadah & Diterima \\
\hline 10 & $\begin{array}{l}\text { Mengunduh template format excel import } \\
\text { data }\end{array}$ & Diterima \\
\hline 11 & Mengexport data excel tempat ibadah & Diterima \\
\hline 12 & Melihat daftar tempat ibadah & Diterima \\
\hline 13 & Melihat Beranda halaman sisi admin & Diterima \\
\hline 14 & Mengubah data tempat ibadah & Diterima \\
\hline 15 & Menghapus data tempat ibadah & Diterima \\
\hline 16 & $\begin{array}{l}\text { Melihat peta lokasi tempat ibadah basis } \\
\text { android }\end{array}$ & Diterima \\
\hline 17 & $\begin{array}{l}\text { Melihat rute lokasi tempat ibadah basis } \\
\text { android }\end{array}$ & Diterima \\
\hline 18 & Melihat peta lokasi tempat ibadah basis web & Diterima \\
\hline 19 & Melihat rute lokasi tempat ibadah basis web & Diterima \\
\hline
\end{tabular}

\section{A.4. Testing}

Pengujian ini bertujuan untuk mengetahui bagaimana kualitas sistem dilihat dari sisi pengguna. Pada pengujian ini dilakukan oleh 31 responden menggunakan kuesioner dan responden diminta untuk mencoba menjalankan sistem, lalu memberikan pernyataan pada pertanyaan berikut.

1. Apakah tampilan aplikasi mudah dipahami?

2. Apakah aplikasi mudah digunakan?

3. Apakah aplikasi ini dapat membantu masyarakat dalam mencari informasi dan lokasi mengenai tempat ibadah yang diinginkan?

4. Apakah aplikasi sudah sesuai dengan kebutuhan pengguna?

5. Apakah aplikasi berjalan dengan baik?

6. Apakah fitur yang disediakan dapat mempermudah pengaksesan aplikasi 
Berikut merupakan hasil grafik persentase rata-rata responden yang telah menggunakan Aplikasi SITABAH (Sistem Informasi Tempat Ibadah), dapat disimpulkan bahwa $40,33 \%$ sangat setuju, $47,85 \%$ setuju, dan $11,83 \%$ terkait dengan kemudahan dalam mengakses aplikasi, tampilan mudah di fahami, aplikasi berjalan dengan baik, membantu pengguna dalam menemukan informasi mengenai tempat ibadah dengan mudah Dapat dilihat pada Gambar 3.

\section{Grafik Persentase rata-rata responden pengguna SITABAH}

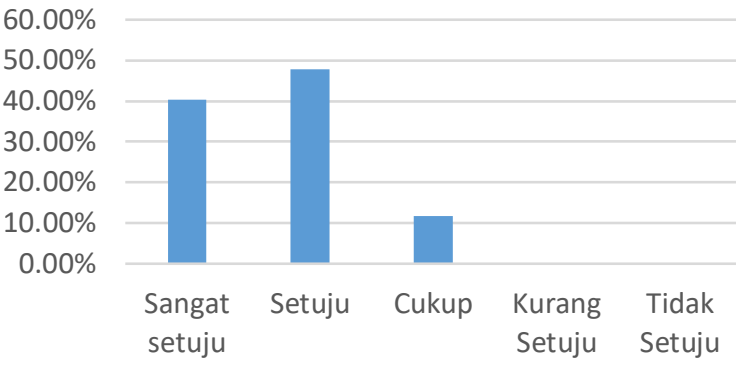

Series 1

Gambar 3. Grafik Perentase rata-rata responden pengguna aplikasi SITABAH

\section{B. Hasil evaluasi metode extreme programming}

Berikut merupakan analisa nilai terhadap metode exreme programming yang telah diimplementasikan selama proses pengembagan sistem berlangsung dapat dilihat pada Tabel VII.

TABEL VII. Hasil ANALisa Nilai Metode EXtREME PROGRAMMING

\begin{tabular}{|l|l|}
\hline Variabel & \multicolumn{1}{|c|}{ Analisa } \\
\hline Communication & $\begin{array}{l}\text { Komunikasi dengan klien memudahkan } \\
\text { pengembang untuk mengetahui sistem yang } \\
\text { diinginkan klien (user stories). Komunikasi } \\
\text { terjadi setiap kali sebuah user stories atau fitur } \\
\text { selesai dikerjakan. Dimana yang menjadi } \\
\text { penghambat pada kegiatan komunikasi ini yaitu } \\
\text { menyesuaikan waktu pertemuan dengan klien. }\end{array}$ \\
\hline Courage & $\begin{array}{l}\text { Keberanian diterapkan pada saat adanya } \\
\text { permintaan penambahan fitur oleh klien. }\end{array}$ \\
& $\begin{array}{l}\text { Hambatan yang terjadi ketika penambahan fitur } \\
\text { yaitu developer harus menerima setiap }\end{array}$ \\
& perubahan, sehingga ketika terdapat fitur yang \\
diminta dirasa cukup sulit untuk dikerjakan, \\
maka akan mengakibatkan waktu pengerjaan \\
yang dibutuhkan akan menjadi lebih lama.
\end{tabular}

\section{KESIMPULAN DAN SARAN}

\section{A. Kesimpulan}

Berdasarkan penelitian dan pembangunan sistem yang telah dilakukan, dapat ditarik beberapa kesimpulan diantaranya:

1. Sistem yang dibuat dapat menyampaikan informasi dan lokasi mengenai data tempat ibadah di Kota Mataram berbasis android dan data tempat ibadah se-NTB berbasis web yang dapat memberikan jalur perjalanan menuju tempat ibadah yang diiginkan dan dapat mengetahui persebaran lokasi tempat ibadah yang ada di provinsi NTB.

2. Dengan adanya sistem yang telah dibuat ini dapat memberikan manfaat bagi masyarakat umum dalam mengetahui informasi dan lokasi tempat ibadah yang ada di Kota Mataram dengan adanya fitur pendukung seperti fitur pencarian, fitur filter berdasarkan kategori jenis tempat ibadah dan filter kabupaten, serta fitur rute menuju lokasi tempat ibadah yang diinginkan. Dapat dibuktikan dengan hasil kuisioner yang yang menunjukkan bahwa 40,33\% sangat setuju, $47,85 \%$ setuju, dan $11,83 \%$ cukup setuju.

3. Dapat membantu mempermudah Kementerian Agama Provinsi NTB dalam melakukan pengelolaan dan pencarian terhadap data tempat ibadah yang ada. Terbukti dari hasil kuesioner yang telah dilakukan oleh 2 pegawai pihak kemenag NTB menunjukkan bahwa $66,67 \%$ sangat setuju, $25 \%$ setuju, dan $8,33 \%$ adalah Cukup terkait dengan kemudahan dalam mengakses aplikasi, tampilan mudah di fahami, aplikasi berjalan dengan baik, membantu pihak kemenag dalam mengelola data tempat ibadah yang ada.

4. Metode Extreme Programming cocok digunakan pada pembuatan aplikasi tempat ibadah ini, karena salah satu karakteristik XP itu sendiri melibatkan client selama proses pembangunan sistem sedangkan dalam kasus penelitian ini pihak Kemenag NTB sebagai client yang terlibat langsung dalam proses perancangan dan pembangunan sistem sehingga berdasarkan hasil pengujian yang telah dilakukan, dapat dikatakan sistem yang dibuat berjalan dengan benar dan telah sesuai dengan kebutuhan client. Terbukti dari dapat dilihat pada hasil pengujian black box pada Tabel VI menunjukkan bahwa seluruh fungsi bekerja dengan baik pada system dan diterima sehingga dapat dikatakan system yang dibuat telah berjalan sesuai dengan fungsi yang dirancang.

\section{B. Saran}

Dikarenakan masih banyak kekurangan dari penulis dalam mengembangkan sistem ini, terdapat beberapa saran untuk dapat membuat sistem ini menjadi lebih baik pada waktu yang akan datang, diantaranya:

1. Device yang digunakan dalam membuat sistem harus diperhatikan terlebih dahulu, karena dalam XP jika terjadi kerusakan device pada saat proses pembuatan sistem berlangsung, maka akan mengganggu estimasi 
pengerjaan system menjadi lebih lama dari yang telah direncanakan.

2. Skill programming pengembang untuk lebih ditingkatkan lagi, agar pada saat proses pengembangan sistem berlangsung menjadikan waktu estimasi pengerjaan yang direncanakan lebih akurat.

3. Sebaiknya aplikasi pada basis android tidak hanya diterapkan di Kota Mataram saja, melainkan dapat diterapkan di provinsi atau di kota-kota lainnya.

4. Sebaiknya sistem yang dibuat disertai dengan fitur dua Bahasa, yaitu Bahasa Inggris dan Bahasa Indonesia untuk membantu pengguna sistem yang tidak berasal dari Indonesia.

5. Pada menu map basis web atau android, sebaiknya ditambahkan polygon atau polyline pada setiap kabupaten atau kecamatan menjadikan sistem informasi yang lebih efektif dalam pembacaan wilayahnya.

6. Desain interface lebih dioptimalkan lagi terutama pada gradasi warna aplikasi mobile-nya.

7. Pada sistem ditampilkan panduan penggunaan aplikasinya agar mempermudah penggunaan sistem bagi orang awam.

\section{DAFTAR PUSTAKA}

[1] Kamus Besar Bahasa Indonesia. Jakarta: PUSAT BAHASA DEPARTEMEN PENDIDIKAN NASIONAL, 2008.

[2] Komite Teknis Perumusan Standar Pelayanan Masyarakat pada Kementerian Lingkungan Hidup dan Kehutanan, "Standar Pelayanan Masyarakat pada Fasilitas Publik Standar." 2016.

[3] M. Agama and D. Negeri, "Pedoman Pelaksanaan Tugas Kepala Daerah/Wakil Kepala Daerah Dalam Pemeliharaan Kerukunan Umat Beragama, Pemberdayaan Forum Kerukunan Umat Beragama, Dan Pendirian Rumah Ibadat," 2006.

[4] G. S. Perdana, "Sistem informasi geografis tempat olahraga di provinsi daerah istimewa yogyakarta berbasis web," 2017.

[5] Sukatmi and F. A. Ani, "Membangun Aplikasi Webgis Untuk Tempat Ibadah Di Provinsi Lampung," Cendikia, vol. XVI, pp. 115-119, 2018.

[6] A. Supriyatna, "Metode Extreme Programming Pada Pembangunan Web Aplikasi Seleksi Peserta Pelatihan Kerja," J. Tek. Inform., vol. 11, no. 1, pp. 1-18, 2018, doi: 10.15408/jti.v11i1.6628.

[7] R. Pamungkas, Implementasi Model Personal Extreme Programming (Pxp) Dalam Pengembangan Sistem Informasi Geografis Pemetaan Flora Dan Fauna Di Taman Nasional Meru Betiri. 2018.

[8] D. Y. Prasetyo and Apriyanto, "Implementasi Geographic Information System (GIS) Penentuan Tampat Ibadah Masjid Di Kecamatan Kempas Kabupaten Indragiri Hilir Provinsi Riau," SISTEMASI, vol. 8, pp. 10-18, 2019.

[9] N. Alamsyah and Wagino, "Sistem Informasi Geografis Persebaran Tempat Ibadah Dan Kapasitasnya Berdasarkan Jumlah Penduduk Di Kota Banjarmasin," Technologia, vol. 9, no. 2, pp. 133-138, 2018 .

[10] C. PARAMITA, "Sistem informasi masjid di surakarta," 2016.

[11] S. Maharani, D. Apriani, A. H. Kridalaksana, P. Studi, I.
Komputer, and U. Mulawarman, "Sistem informasi geografis pemetaan masjid di samarinda berbasis web," vol. 11, pp. 9-20, 2017.

[12] W. N. NUGROHO, "Aplikasi Pencarian Masjid Terdekat Di Kota Bandar Lampung Berbasis Mobile Menggunakan Algoritma Dijkstra," 2017.

[13] R. S. HAMSYAH, "Rancang Bangun Aplikasi Go-Ban Untuk Mencari Dan Memanggil Teknisi Tambal Ban Menggunakan Google Maps Api,” 2018.

[14] Suhartini, M. Sadali, and Y. K. Putra, "Sistem Informasi Berbasis Web Sma Al- Mukhtariyah Mamben Lauk Berbasis Php Dan Mysql Dengan Framework Codeigniter," infotek, vol. 3, no. 1, pp. 79-84, 2020.

[15] M. Arifin and R. H. H. Hs, "Perancangan Sistem Informasi Pusat Karir Sebagai Upaya Meningkatkan Relevansi Antara Lulusan Dengan Dunia Kerja Menggunakan UML," IC-Tech, vol. XII, no. 2, pp. 42-49, 2017.

[16] T. Sutabri, KONSEP SISTEM INFORMASI. Yogyakarta, 2012.

[17] A. Solichin, "Pemrograman Web dengan PHP dan MySQL," pp. 1-122.

[18] B. Utama, "Aplikasi Peminjaman Dan Pengembalian Barang Menggunakan Rfid Dan Barcode Scanner Berbasis Web," 2019.

[19] T. Kahlert and K. Giza, "Visual Studio Code - Code Editing. Redefined," Mikrosoft, vol. 1, no. March, pp. 126, 2016.

[20] A. Krismadi, A. F. Lestari, A. Pitriyah, I. W. P. A. Mardangga, M. Astuti, and A. Saifudin, "Pengujian Black Box berbasis Equivalence Partitions pada Aplikasi Seleksi Promosi Kenaikan Jabatan," J. Teknol. Sist. Inf. dan Apl., vol. 2, no. 4, p. 155, 2019, doi: 10.32493/jtsi.v2i4.3771.

[21] W. Widyantoro, "Buku Panduan Bootstrap," 2015.

[22] M. Lenz, "Postman," Python Contin. Integr. Deliv., pp. 112, 2019, doi: 10.1007/978-1-4842-4281-0_1.

[23] M. Ichwan and F. Hakiky, "Pengukuran Kinerja Goodreads Application Programming Interface (API) Pada Aplikasi Mobile Android (Studi Kasus Untuk Pencarian Data Buku)," vol. 2, no. 2, pp. 13-21, 2011.

[24] J. Andi, "Pembangunan Aplikasi Child Tracker Berbasis Assisted - Global Positioning System ( A-GPS ) Dengan Platform Android," J. Ilm. Komput. dan Inform., vol. 1, no. 1, pp. 1-8, 2015.

[25] P. Abrahamson, Outi Salo, Jussi Ronkainen, and Juhani Warsta, "Agile software development methods: Review and analysis," VTT Publ., p. 112, 2002.

[26] A. Prasetya, A. H. Brata, and M. T. Ananta, "Pengembangan Aplikasi Pemesanan Lapangan Futsal Di Kota Malang Berbasis Android Menggunakan Metode Pengembangan Extreme Programming (Studi Kasus Champion Tidar, Zona SM Futsal, dan Viva Futsal)," $J$. Pengemb. Teknol. Inf. dan Ilmu Komput. Univ. Brawijaya, vol. 2, no. 12, pp. 7293-7301, 2018.

[27] A. Lisna, "Extreme Programming," J. Chem. Inf. Model., vol. 53, no. 9, pp. 1689-1699, 2016, doi: 10.1017/CBO9781107415324.004.

[28] M. Ulfi, G. I. Marthasari, and N. Ilyas, "Implementasi Metode Personal Extreme Programming dalam Pengembangan Sistem Manajemen Transaksi Perusahaan (Studi Kasus: CV. Todjoe Sinar Group),” vol. 2, no. 3, pp. 261-268, 2020.

[29] R. Agarwa and D. Umphress, "Extreme programming for a single person team," Proc. 46th Annu. Southeast Reg. Conf. $X X, A C M-S E$ 46, no. August, pp. 82-87, 2008, doi: $10.1145 / 1593105.1593127$ 
[30] R. A. Azdy and A. Rini, "Penerapan Extreme Programming Dalam Membangun Aplikasi Pengaduan Layanan Pelanggan (Palapa) Pada Perguruan Tinggi," vol. 5, no. 2, pp. 197-206, 2018, doi: 10.25126/jtiik.201852658.

[31] M. A. F. Z and A. Wibowo, "Aplikasi gameplay edukasi pencegahan obesitas dengan menggunakan algoritma astar dan greedy pada pencarian jalur makanan," vol. 10, no. 2016.

[32] A. Mu, "BAB III, metodologi penelitian," J. Chem. Inf. Model., vol. 53, no. 9, pp. 1689-1699, 2019, doi: 10.1017/CBO9781107415324.004.

[33] A. N. A. Thohari and A. E. Amalia, "Implementasi Test Driven Development Dalam Pengembangan Aplikasi Berbasis Web," SITECH J. Sist. Inf. dan Teknol., vol. 1, no. 1, pp. 1-10, 2018, doi: 10.24176/sitech.v1i1.2255.

[34] S. Masripah and L. Ramayanti, "Penerapan Pengujian
Alpha Dan Beta Pada Aplikasi Penerimaan Siswa Baru," $J$. Swabumi, vol. 8, no. 1, pp. 100-105, 2020.

[35] A. B. Mutiara, U. Gunadarma, A. Muslim, U. Gunadarma, T. Oswari, and U. Gunadarma, "Testing Implementasi Website Rekam Medis Elektronik Opeltgunasys Dengan Metode Acceptance Testing," no. February 2016, 2014, doi: 10.13140/RG.2.1.1159.5286.

[36] R. A. Lestari, "Pengaruh Kepemimpinan Partisipatif D an Komitmen Organisasi Terhadap Efektifitas Implementasi Rencana Stratejik Pada Madrasah Aliyah D i Kabupaten Sukabumi," pp. 1-25, 2014.

[37] A. Suandi, F. N. Khasanah, and E. Retnoningsih, "Pengujian Sistem Informasi E-commerce Usaha Gudang Cokelat Menggunakan Uji Alpha dan Beta," Inf. Syst. Educ. Prof., vol. 2, no. 1, pp. 61-70, 2017. 